\title{
QUALIDADE DO ABACATE 'HASS' FRIGOARMAZENADO SUBMETIDO A ATMOSFERAS MODIFICADAS ATIVAS ${ }^{1}$
}

\author{
ROGÉRIO LOPES VIEITES², VIVIANE CITADINI RUSSO ${ }^{3}$, ÉRICA REGINA DAIUTO ${ }^{4}$
}

RESUMO-O objetivo deste trabalho foi avaliar a conservação do abacate 'Hass' frigoarmazenado submetido a atmosferas modificadas ativas. Os frutos foram acondicionados em embalagem de náilon+polietileno e submetidos à injeção de mistura de gases, constituindo os tratamentos: I - mistura gasosa do ambiente $(21,0$ $\mathrm{kPa}$ de $\mathrm{O}_{2}+0,03 \mathrm{kPa}$ de $\mathrm{CO}_{2}$ ); II - 4,0 $\mathrm{kPa}$ de $\mathrm{O}_{2}+5,0 \mathrm{kPa}$ de $\mathrm{CO}_{2}$; III - 4,0 $\mathrm{kPa}$ de $\mathrm{O}_{2}+6,0 \mathrm{kPa}$ de $\mathrm{CO}_{2}$; IV - 4,0 $\mathrm{kPa}$ de $\mathrm{O}_{2}+7,0 \mathrm{kPa}$ de $\mathrm{CO}_{2}$ e V $-4,0 \mathrm{kPa}$ de $\mathrm{O}_{2}+8,0 \mathrm{kPa}$ de $\mathrm{CO}_{2}$ ). As embalagens contendo os frutos foram armazenadas em câmara frigorífica, a uma temperatura de $10 \pm 1^{\circ} \mathrm{C}$ e umidade relativa de $90 \pm 5 \%$, durante 25 dias, sendo as análises realizadas a cada 5 dias. As análises realizadas foram perda de massa, atividade respiratória, potencial hidrogeniônico $(\mathrm{pH})$, firmeza, acidez titulável (AT), sólidos solúveis (SS) e atividade das enzimas pectinametilesterase (PME) e poligalacturonase (PG). O tratamento em que os frutos foram submetidos à pressão parcial de $4,0 \mathrm{kPa}$ de $\mathrm{O}_{2}+7,0 \mathrm{kPa}$ de $\mathrm{CO}_{2}$ foi o mais efetivo na conservação dos frutos, principalmente pela menor perda de massa e baixa produção de $\mathrm{CO}_{2}$.

Termos para indexação: Persea americana Mill, pós-colheita, embalagem.

\section{AVOCADO 'HASS' QUALITY SUBJECTED TO MODIFIED ATMOSPHERES AND COLD STORAGE}

\begin{abstract}
The objective of this study was to evaluated conservation of 'Hass' avocado submitted to the application of active modified atmosphere during cold storage. The fruits were packed in polyethylene+nylon and injected with mixture of gases constituting the treatments: I - the environment gas mixture $(21.0 \mathrm{kPa}$ of $\mathrm{O}_{2}+0.03 \mathrm{kPa}$ of $\mathrm{CO}_{2}$ ); II $-4.0 \mathrm{kPa}$ of $\mathrm{O}_{2}+5.0 \mathrm{kPa}$ of $\mathrm{CO}_{2}$; III $-4.0 \mathrm{kPa}_{2} \mathrm{O}_{2}+6.0 \mathrm{kPa}$ of $\mathrm{CO}_{2}$; IV $-4.0 \mathrm{kPa}$ of $\mathrm{O}_{2}+7.0 \mathrm{kPa}$ of $\mathrm{CO}_{2}$ and $\mathrm{V}-4.0 \mathrm{kPa}$ of $\mathrm{O}_{2}+8.0 \mathrm{kPa}$ of $\mathrm{CO}_{2}$ ). The packing containing the fruits were stored in cold chamber at a temperature of $10 \pm 1^{\circ} \mathrm{C}$ and relative humidity of $90 \pm 5 \%$, for 25 days, with analyses performed every 5 days. The parameters evaluated were weight loss, respiratory activity, hydrogen potential $(\mathrm{pH})$, firmness, titrable acidity (TA), soluble solids (SS), and activity of pectinmethylesterase (PME) and polygalacturonase (PG). Fruits submitted to the concentration of $4.0 \mathrm{kPa}$ of $\mathrm{O}_{2}+7.0 \mathrm{kPa}$ showed the best quality mainly with less mass loss and low production of $\mathrm{CO}_{2}$.

Index terms: Persea americana Mill, postharvest, packing.
\end{abstract}

(Trabalho 162-13). Recebido em: 05-04-2013. Aceito para publicação em: 07-03-2014 .

${ }^{2}$ Prof. Titular Departamento de Horticultura da Faculdade de Ciências Agronômicas da UNESP-Botucatu. E-mail: vieites@fca.unesp.br ${ }^{3}$ Mestre pelo curso Energia na Agricultura na Faculdade de Ciências Agronômicas da Universidade Estadual Paulista "Julio de Mesquita Filho". E-mail: vivianecitadini@hotmail.com

${ }^{4}$ Pós Doutoranda (CAPES/PNPD) no curso Horticultura na Faculdade de Ciências Agronômicas da Universidade Estadual Paulista "Júlio de Mesquita Filho". E-mail: erdaiuto@uol.com.br 


\section{INTRODUÇÃO}

O abacate (Persea americana Mill.) apresenta elevado valor nutritivo e é muito valorizado no mercado externo, sendo as variedades Hass e Fuerte as mais comercializadas. Estes frutos apresentam menor diâmetro, maior teor de lipídeos, casca mais grossa em relação à cultivar tipo manteiga, e menor teor de água, o que torna a polpa mais consistente, possibilitando sua utilização em pratos salgados.

No mercado brasileiro, estes abacates são comercializados com a denominação de "avocado", uma estratégia de marketing para valorizar o fruto e induzir o consumo do mesmo de maneira diferenciada, do mesmo modo que é utilizado nos outros países e não como sobremesa, que é de costume no Brasil. Grande parte da produção destes frutos destina-se a à exportação, e algumas empresas possuem como diferencial o selo de certificação Global Gap. O custo de produção do "avocado" é superior às variedades comercializadas no mercado brasileiro devido ao fato de a colheita ser totalmente manual para atender ao padrão de exportação.

$\mathrm{O}$ abacate é fruto climatérico que amadurece rapidamente após a colheita (SEYMOUR; TUCKER, 1993) e o comportamento pós-colheita pode ser influenciado pela temperatura e pelo tempo de armazenamento (TEIXEIRA et al., 1991). A literatura aponta estudos relacionados ao aumento do período de conservação de abacate, como avaliação da temperatura de armazenamento, uso de atmosfera modificada com aplicação de cera, irradiação gama, UV-C e tratamento térmico (VIEITES et al., 2012), sendo o armazenamento em baixas temperaturas, logo em seguida à colheita, a técnica mais utilizada para prolongar a conservação dos frutos.

A aplicação de atmosferas modificadas ou controladas envolve a redução dos níveis de oxigênio e a elevação de gás carbônico, resultando no prolongamento do tempo de maturação e, portanto, do período de comercialização. Brackmann et al. (1999) citam que tradicionalmente os produtores usam filmes de PVC esticável de baixa espessura para acondicionar as frutas nas embalagens comerciais. Aumentando-se a espessura dos filmes, diminui-se sua permeabilidade, possibilitando maior acúmulo de $\mathrm{CO}_{2}$ e aumentando a vida pós-colheita das frutas. Estes autores mencionam que há concentrações ideais de $\mathrm{O}_{2}$ e $\mathrm{CO}_{2}$ para que as qualidades físicoquímicas das frutas sejam conservadas sem que ocorra respiração anaeróbia e o consequente acúmulo de álcoois. Portanto, o conhecimento prévio das características de cada fruto é essencial para o sucesso desta tecnologia.
O objetivo desta pesquisa foi avaliar o efeito de diferentes concentrações de atmosfera modificada ativa na qualidade pós-colheita dos abacates 'Hass'.

\section{MATERIAL E MÉTODOS}

Foram utilizados frutos de abacate 'Hass', da safra de 2010, colhidos no ponto de maturação fisiológica (de acordo com o teor de óleo, 21,6\%) fornecidos pela empresa Jaguacy, localizada em Bauru-SP, cujas coordenadas geográficas são: latitude 22 $2^{\circ} 19^{\prime} 18^{\prime \prime} \mathrm{S}$, longitude 4904'13” W e 526 $\mathrm{m}$ de altitude, distante $90 \mathrm{~km}$ de Botucatu: latitude de $22^{\circ} 52^{\prime} 20^{\prime \prime} \mathrm{S}$, longitude $48^{\circ} 26^{\prime} 37^{\prime}$ ' W e $815 \mathrm{~m}$ de altitude. Os frutos foram inicialmente armazenados na temperatura de $10 \pm 1^{\circ} \mathrm{C}$, por 12 horas, para que ocorresse a diminuição do metabolismo dos frutos. Antes da instalação do experimento, os frutos foram selecionados, visando à homogeneização do lote quanto à ausência de danos físicos. Os frutos foram lavados com água e detergente, no intuito de remover resíduos da colheita e reduzir colônias de microrganismos aderidos à superfície. A higienização dos abacates foi realizada com uma solução de hipoclorito de sódio a $1 \%$, por aproximadamente 20 minutos.

Os tratamentos foram constituídos, utilizando-se da atmosfera modificada ativa nos frutos inteiros acondicionados em embalagem de náilon + polietileno, com dimensões de $30 \times 25 \times 0,14$ $\mathrm{cm}$ e permeabilidade parcial à entrada e saída de $\mathrm{CO}_{2}$ e $\mathrm{O}_{2}$ nos tratamentos de II a $\mathrm{V}$, sendo designado o tratamento I como tratamento-controle, ou seja, sem modificação da atmosfera interna da embalagem, conforme Tabela 1. A embalagem utilizada para o tratamento-controle foi a de polietileno de baixa densidade. A mistura gasosa foi obtida pronta da empresa White Martins, sendo os cilindros de gases acoplados a uma seladora, e o procedimento consistiu na formação de vácuo seguida da injeção dos gases e selamento da embalagem. O tratamento I (tratamento-controle, sem aplicação dos gases) foi apenas selado, constituindo-se da mistura de gases do próprio ambiente.

As análises realizadas foram perda de massa, atividade respiratória, potencial hidrogeniônico, acidez titulável, sólidos solúveis, firmeza, atividade das enzimas pectinametilesterase e poligalacturonase.

A instalação do experimento consistiu no acondicionamento de três abacates por embalagem, sendo cada embalagem uma repetição, totalizando três embalagens por tratamento em cada dia de análise. Considerando no tempo zero o uso de três embalagens para análises, o experimento totalizou 
234 frutos para análises destrutivas e a mesma quantidade para perda de massa e respiração.

Após a injeção de gases e o selamento das embalagens, estas foram acondicionadas em câmara frigorífica à temperatura de $10 \pm 1^{\circ} \mathrm{C}$ e umidade relativa de $90 \pm 5 \%$, durante 25 dias, sendo as avaliações a cada cinco dias.

A perda de massa fresca foi determinada pela pesagem dos frutos em balança semi- analítica da marca OWLABOR - carga máxima de $2.000 \mathrm{~g}$ e precisão de $0,01 \mathrm{~g}$, considerando a massa inicial de cada amostra, com os resultados expressos em percentagem.

A respiração foi determinada pela liberação de $\mathrm{CO}_{2}$ em cada embalagem, de acordo com metodologia adaptada de Bleinroth et al. (1976), utilizando-se para isso da solução de hidróxido de bário saturado e solução de hidróxido de potássio $0,1 \mathrm{~N}$. Para tanto, foi utilizada a seguinte fórmula:

$$
\mathrm{TCO}_{2}=\frac{2,2\left(\mathrm{Vo}^{-\mathrm{V}_{1}}\right) \cdot 10}{\text { P.T }}
$$

em que,

$\mathrm{TCO}_{2}=$ taxa de respiração $\left(\mathrm{mL} \mathrm{de} \mathrm{CO}_{2} \mathrm{~kg}^{-1} \mathrm{~h}^{-1}\right)$; $\mathrm{Vo}=$ volume gasto de $\mathrm{HCl}$ para titulação de hidróxido de potássio - padrão antes da absorção de $\mathrm{CO}_{2}(\mathrm{~mL})$;

$\mathrm{V}_{1}=$ volume gasto de $\mathrm{HCl}$ para titulação de hidróxido de potássio após a absorção de $\mathrm{CO}_{2}$ da respiração $(\mathrm{mL})$;

$\mathrm{P}=$ massa dos frutos;

$\mathrm{T}=$ tempo da respiração;

2,2 = inerente ao equivalente de $\mathrm{CO}_{2}(44 / 2)$, multiplicado pela concentração do ácido clorídrico, e

$10=$ ajuste para o total de hidróxido de potássio utilizado.

Os teores de sólidos solúveis (SS), $\mathrm{pH}$ e acidez titulável (AT) foram determinados seguindo as Normas Analíticas do Instituto Adolf Lutz (2008). $\mathrm{O}$ teor de sólidos solúveis foi medido, em leitura refratométrica em ${ }^{\circ} \mathrm{Brix}$, a $20^{\circ} \mathrm{C}$, com refratômetro digital, conforme metodologia.

A avaliação da firmeza da polpa foi feita utilizando-se de texturômetro STEVENS - LFRA Texture Analyser, com a distância de penetração de $20 \mathrm{~mm}$, velocidade de $2,0 \mathrm{~mm} \mathrm{seg}^{-1}$ e ponta de prova TA 9/1000, e os resultados foram apresentados em gramas-força $^{-1}$. Foram realizadas cinco leituras para cada uma das 3 repetições, no terço médio dos frutos, em todos os tratamentos.

A atividade da pectinametilesterase (PME) foi determinada segundo Hultin et al. (1966). Um mililitro do extrato enzimático foi adicionado sobre
$30 \mathrm{~mL}$ de pectina cítrica a $1 \%$ em $\mathrm{NaCl} 0,2 \mathrm{~N}$. O $\mathrm{pH}$ da solução foi mantido em torno de 7,0 , por dez minutos. Uma unidade de PME foi definida como a quantidade de enzima capaz de catalisar a desmetilação de pectina correspondente ao consumo de $1 \mathrm{nmol}$ de $\mathrm{NaOH} \min ^{-1} \mathrm{~g}^{-1}$ de massa fresca, nas condições do ensaio. $\mathrm{O}$ resultado foi expresso em U.E. $\min ^{-1}$ grama de tecido ${ }^{-1}$.

A determinação da atividade da poligalacturonase $(\mathrm{PG})$ foi realizada segundo o método de Buescher e Furmanshi (1978), com modificações, utilizando-se de $5 \mathrm{~g}$ de polpa do fruto congelado, homogeneizado em polytron, com água destilada gelada. O homogenato foi filtrado em tecido fino (organza), e o resíduo ressuspendido em $\mathrm{NaCl} 1 \mathrm{~N}$ resfriado. $\mathrm{O} \mathrm{pH}$ foi ajustado para 6,0 , com auxílio de $\mathrm{NaOH} 0,01 \mathrm{~N}$, e o extrato foi incubado a $4^{\circ} \mathrm{C}$ por uma hora. $\mathrm{O}$ extrato foi novamente filtrado em papel- filtro e utilizado para a determinação da atividade enzimática, sendo incubado em solução de $0,25 \%$ de pectina cítrica a $30^{\circ} \mathrm{C}$ por 3 horas. A reação foi interrompida com banho fervente e os grupos redutores liberados, determinados pela técnica de Somogy (1945) e Nelson (1944). Uma unidade de PG foi definida como a quantidade de enzima capaz de catalisar a formação de $1 \mathrm{hmol}$ de grupos redutores por minuto, nas condições de ensaio. Os resultados foram expressos em U.E. min-1 g-1.

O experimento foi conduzido em delineamento inteiramente casualizado (DIC), compostos por cinco tratamentos e seis tempos de armazenamento, compondo um fatorial $5 \times 6$.

Os resultados foram submetidos à análise de variância, e as médias foram comparadas pelo teste Scott-Knott, ao nível de 1 ou 5\% de probabilidade, conforme a característica avaliada.

\section{RESULTADOS E DISCUSSÃO}

\section{PERDA DE MASSA FRESCA}

Observou-se perda de massa fresca em todos os tratamentos ao longo dos 25 dias de armazenamento, dos quais o tratamento-controle (TI) apresentou a maior perda de massa, seguido do $\mathrm{TV}$, conforme pode ser observado na média geral dos tratamentos. O tratamento IV mostrou a menor perda de massa durante o período experimental, sendo que o aumento do percentual de perda de massa ocorreu apenas após o vigésimo dia de armazenamento. O tratamento II também mostrou perda de massa inferior aos demais tratamentos com aumento do percentual de perda de massa a partir do décimo 
quinto dia de armazenamento (Tabela 2).

Joyce et al. (1995) relataram que abacates 'Hass' armazenados à temperatura constante de $22^{\circ} \mathrm{C}$ apresentaram média de perda de mana diária de $0,99 \%$, e quando os mesmos foram tratados com a cera produzida pela firma Colin Campbell Chemistry, a perda de mana diária foi de $0,51 \%$. Daiuto et al. (2010a) também observaram que, nos frutos 'Hass' armazenados sob refrigeração $\left(10^{\circ} \mathrm{C}\right)$, para qualquer tipo de tratamento físico realizado (irradiação gama, UV-C e tratamento térmico a $45^{\circ} \mathrm{C}$ ), a perda de massa foi inferior nos frutos armazenados sob temperatura ambiente em relação aos demais tratamentos. Ainda Daiuto et al. (2010a) encontraram percentuais de perda de massa superiores aos desta pesquisa, variando de 1,8 a $3,5 \%$,dos $3^{\circ}$ ao $15^{\circ}$ dia de armazenamento. Apesar de as condições experimentais e tratamentos realizados serem distintos, pode-se sugerir que a atmosfera modificada ativa contribuiu de forma efetiva para a redução da perda de massa dos frutos de abacate 'Hass', fato comprovado também neste experimento, ao observado pelo comportamento do tratamento-controle.

\section{ATIVIDADE RESPIRATÓRIA}

Os frutos do tratamento-controle (TI) mostraram maior produção de $\mathrm{CO}_{2}$ aos 10 dias de armazenamento, bem como os frutos do tratamentos TIII, mas com menor intensidade na produção deste gás. Daiuto et al. (2010a) avaliaram taxa respiratória de abacate 'Hass' com frutos submetidos a diferentes tratamentos físicos (térmico a $45^{\circ} \mathrm{C}$, UV e radiação gama), e constataram para todos tratamentos que o pico respiratório foi em torno do nono dia de armazenamento. Os frutos dos tratamentos IV e V apresentam produção menos intensa de $\mathrm{CO}_{2}$ durante o período experimental. Apesar dos tratamentos, o tratamento térmico diminui a intensidade do pico respiratório dos frutos.

Dorria et al. (2003) também avaliaram o efeito da atmosfera modificada no armazenamento de abacates 'Hass" e 'Fuerte', usando concentrações de $2 \mathrm{kPa}$ de $\mathrm{O}_{2}$ e 5 ou $8 \mathrm{kPa}$ de $\mathrm{CO}_{2}$. Os frutos eram mantidos a $5^{\circ} \mathrm{C}$ e, semanalmente, transferidos para temperatura de $20^{\circ} \mathrm{C}$. As avaliações foram realizadas nas condições de armazenamento para amadurecimento, ou seja, $20^{\circ} \mathrm{C}$. Os autores observaram uma relação íntima entre troca de gás e comportamento de fruta ao longo do amadurecimento e do armazenamento. Os tratamentos de atmosfera modificada mostraram redução na taxa de respiração de frutas de abacate em ambas as cultivares, as quais apresentaram o mesmo padrão de produção de $\mathrm{CO}_{2}$.

\section{ACIDEZ TITULÁVEL}

A acidez titulável dos abacates 'Hass' foi influenciada significativamente pelos tratamentos, apenas no $5^{\circ}$ dia de armazenamento, quando os frutos do tratamento $\mathrm{T} 1$ apresentaram os mais altos teores de acidez (Tabela 3). Com o decorrer do armazenamento, observou-se redução significativa dos teores de acidez titulável em todos os tratamentos. Chitarra e Chitarra (2005) relataram que, com o amadurecimento, a maioria dos frutos perde rapidamente a acidez, geralmente devido ao consumo dos ácidos ou da conversão em açúcares, pois os mesmos são considerados reserva de energia e são utilizados na atividade metabólica no processo de amadurecimento.

\section{POTENCIAL HIDROGENIÔNICO}

Para o potencial hidrogeniônico, não ocorreu diferença entre os tratamentos, no entanto observouse efeito significativo nos valores médios de pH no decorrer dos dias de armazenamento. Notou-se aumento dos valores de 6,6 no $5^{\circ}$ dia de armazenamento para 7,0 no $20^{\circ}$ dia, quando observadas a média geral dos dias (Tabela 3). Este resultado pode ter sido consequência da redução da acidez titulável que pode ocorrer nos frutos durante o amadurecimento.

Nos trabalhos realizados por Daiuto et al. (2010a), em abacate 'Hass' submetidos a diferentes tratamentos físicos, e Oliveira et al. (2000), em abacate 'Fuerte' submetido à aplicação de cera vegetal, os autores observaram estabilidade nos valores de $\mathrm{pH}$ durante o armazenamento.

\section{SÓLIDOS SOLÚVEIS}

Nos teores de sólidos solúveis dos frutos de abacate 'Hass', observou-se efeito significativo ao longo do armazenamento, para as diferentes concentrações e para a interação concentrações $\mathrm{x}$ dias. Observou-se diminuição dos valores de sólidos solúveis ao longo dos dias de armazenamento quando observada a média geral de dias (Tabela 3 ).

Observou-se maior teor médio de SS para o tratamento T5 (9,7 ${ }^{\circ}$ Brix), e possivelmente este resultado foi consequência da maior perda de massa destes frutos em relação aos demais tratamentos.

\section{FIRMEZA}

Nesta pesquisa, não houve diferença significativa nos valores da firmeza para os frutos de abacate 'Hass' dos diferentes tratamentos e para interação concentração $\mathrm{x}$ dias de armazenamento 
(Tabela 4). Deve-se levar em consideração que a firmeza é um importante atributo na qualidade dos frutos, já que afeta a resistência ao transporte, ao ataque de microrganismos e à própria característica sensorial dos frutos (BÁEZ-SAÑUDO et al., 2001).

O decréscimo dos valores deve-se ao fato de a firmeza estar estreitamente relacionada com a solubilização de substâncias pécticas e que, durante a maturação, ocorre a conversão da pectina insolúvel em pectina solúvel, amolecendo e diminuindo a resistência dos frutos, conforme explicaram Chitarra e Chitarra (2005), fato não ocorrido neste experimento.

Ben-Arie e Zutkhi (1992) verificaram que o uso da atmosfera modificada ativa em caqui também retarda a perda de firmeza e inibe o desenvolvimento de desordens na polpa e epiderme dos frutos. Neste experimento, o uso da atmosfera modificada, juntamente com o armazenamento refrigerado nos frutos de abacate 'Hass', apresentou o mesmo efeito.

Ahmed et al. (2007), em estudo de atmosfera modificada em abacates 'Hass' e 'Furte', conforme mencionado, observaram na concentração de $8 \mathrm{kPA}$ de $\mathrm{CO}_{2}$, baixo percentual de perda de massa e valores de firmeza mais elevados. Na presente pesquisa, tal fato não ficou evidente, pois a perda de massa dos frutos também foi reduzida, provavelmente em função do armazenamento e da avaliação dos frutos sob condições de refrigeração.

\section{ATIVIDADE DA ENZIMA PECTINAMETILESTERASE (PME)}

Houve aumento dos valores da atividade da PME ao longo dos dias de armazenamento. A média geral mostra que as concentrações de $6,0 \%$ e 7,0\% de $\mathrm{CO} 2$ apresentaram as menores atividades de PME (Tabela 5). A atividade da enzima aumentou até o $15^{\circ}$, $20^{\circ}$ e $25^{\circ}$ dia de armazenamento, respectivamente, para os tratamentos T I; T II e T III; T IV e T V.

O comportamento da enzima PME pode variar de acordo com a espécie. A atividade desta enzima pode aumentar em mamão (LOURENÇO;CATUTANI, 1984), maçã (JOHNSTON et al., 2002), pêssego (OLIVIEIRA et al., 2005), framboesa (IANNETTA et al., 1999), carambola (CHIN et al., 1999), pera (BRUMMELL et al., 2004), tomate (HOBSON, 1963) e banana (SALES et al., 2004), ou diminuir em abacate (AWAD; YOUNG, 1979), manga (PRASANNA et al., 2003) e tomate (RESENDE et al., 2004).

Awad e Young (1979) observaram que parcial desmetilação da pectina é necessária antes que a PG possa trazer significante hidrólise. Então, a PME pode ter a função de preparar o substrato para ser hidrolisado pela PG. Os autores observaram que, quando houve diminuição abrupta da PME, iniciouse o aumento da PG.

\section{ATIVIDADE DA ENZIMA POLIGALACTURONASE (PG)}

Os resultados para a $\mathrm{PG}$ nos frutos de abacate 'Hass' foram significativos para os dias e para a interação concentrações x dias, não havendo significância para as diferentes concentrações utilizadas, isso devido à grande oscilação da atividade da PG (Tabela 4).

Resultado semelhante foi observado em tomate (FILGUEIRAS, 1996), em que a atividade da enzima PG oscilou durante o amadurecimento dos frutos. Apesar desta oscilação, pode-se observar maior atividade da $\mathrm{PG}$ no $5^{\circ}$ e $25^{\circ}$ dias de armazenamento nos abacates 'Hass'.

Contudo, esta atividade não influenciou na firmeza dos frutos, sendo que os tratamentos que apresentaram maior e menor atividade da $\mathrm{PG}$, também apresentaram maior e menor firmeza, respectivamente. Sales et al. (2004) também não observaram relação direta entre a atividade da PG e a solubilização da pectina.

Ahmed et al. (2007) avaliaram atividade das enzimas celulase e pectinase em abacates Hass e Furtes submetidos a atmosfera modificada e avaliados a $20^{\circ} \mathrm{C}$. Os autores observaram que a atividade de celulase mostrou grande aumento como papel principal, amolecimento de frutas de abacate, enquanto atividade de pectinase diminuiu em frutas armazenadas sob condições de atmosfera modificada com menores valores a concentrações de $\mathrm{CO}_{2}$ mais elevadas. 
TABELA 1- Descrição dos tratamentos.

\begin{tabular}{|c|c|c|}
\hline Tratamentos & $\mathbf{k P a} \mathbf{O}_{\mathbf{2}}$ & $\mathbf{k P a} \mathbf{C O}_{\mathbf{2}}$ \\
\hline I & 21 & 0,03 \\
\hline II & 4 & 5 \\
\hline III & 4 & 6 \\
\hline IV & 4 & 7 \\
\hline V & 4 & 8 \\
\hline
\end{tabular}

TABELA 2- Perda de massa (\%) de abacates 'Hass' submetidos à atmosfera modificada ativa armazenados em câmara frigorífica à $10 \pm 1^{\circ} \mathrm{C}$ com $90 \pm 5 \%$ de UR, por 35 dias.

\begin{tabular}{|c|c|c|c|c|c|c|c|}
\hline & \multicolumn{6}{|c|}{ Dias de armazenamento } & \multirow[b]{2}{*}{$\begin{array}{l}\text { Média geral de } \\
\text { tratamento }\end{array}$} \\
\hline Tratamento & $\mathbf{0}$ & 5 & 10 & 15 & 20 & 25 & \\
\hline $\mathrm{I}$ & $0,0 \mathrm{aA}$ & $0,03 \mathrm{aA}$ & $0,47 \mathrm{bB}$ & $0,65 \mathrm{cB}$ & $0,71 \mathrm{cC}$ & $0,73 \mathrm{cC}$ & $0,518 \mathrm{a}$ \\
\hline II & $0,0 \mathrm{aA}$ & $0,01 \mathrm{aA}$ & $0,04 \mathrm{aA}$ & $0,01 \mathrm{aA}$ & $0,39 \mathrm{bB}$ & $0,44 \mathrm{bB}$ & $0,196 \mathrm{~b}$ \\
\hline III & $0,0 \mathrm{aA}$ & $0,01 \mathrm{aA}$ & $0,05 \mathrm{aA}$ & $0,25 \mathrm{bB}$ & $0,23 \mathrm{bB}$ & $1,42 \mathrm{cC}$ & $0,392 \mathrm{c}$ \\
\hline IV & $0,0 \mathrm{aA}$ & $0,03 \mathrm{aA}$ & $0,04 \mathrm{aA}$ & $0,06 \mathrm{aA}$ & $0,09 \mathrm{aA}$ & $0,49 \mathrm{bA}$ & $0,142 b$ \\
\hline $\mathrm{V}$ & $0,0 \mathrm{aA}$ & $0,01 \mathrm{aA}$ & $0,69 \mathrm{bB}$ & $0,64 \mathrm{bB}$ & $0,51 \mathrm{cB}$ & $1,12 \mathrm{cC}$ & $0,594 \mathrm{a}$ \\
\hline Média geral de dia & & $0,018 \mathrm{~A}$ & $0,258 \mathrm{~B}$ & $0,34 \mathrm{C}$ & $0,386 \mathrm{C}$ & $0,84 \mathrm{D}$ & \\
\hline
\end{tabular}

Médias seguidas de mesma letra para os dias e para as concentrações não diferem entre si pelo Teste Skott-Knott à 1\% de probabilidade. Médias seguidas de mesma letra minúscula na linha e maiúscula na coluna para a interação concentrações X dias não diferem entre si pelo Teste Scott-Knott à $1 \%$ de probabilidade.

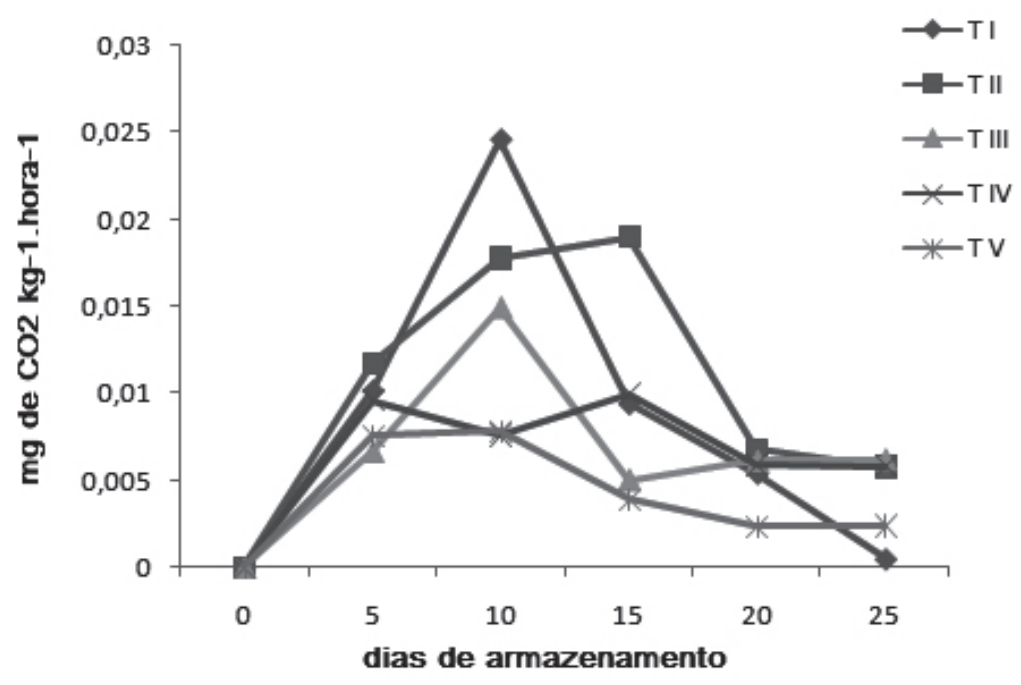

Legenda: TI- 21,0 kPa de $\mathrm{O}_{2}+0,03 \mathrm{kPa}$ de $\mathrm{CO}_{2}$ ); TII- 4,0 kPa de $\mathrm{O}_{2}+5,0 \mathrm{kPa}$ de $\mathrm{CO}_{2}$; TIII - 4,0 kPa de $\mathrm{O}_{2}+6,0 \mathrm{kPa}$ de $\mathrm{CO}_{2}$; TIV- 4,0 $\mathrm{kPa}$ de $\mathrm{O}_{2}+7,0 \mathrm{kPa}$ de $\mathrm{CO}_{2}$ e TV- $4,0 \mathrm{kPa}$ de $\mathrm{O}_{2}+8,0 \mathrm{kPa}$ de $\mathrm{CO}_{2}$

FIGURA 1 - Taxa respiratória $\left(\mathrm{mL}\right.$ de $\left.\mathrm{CO}_{2} \mathrm{~kg}^{-1} \mathrm{~h}^{-1}\right)$ obtida em abacates 'Hass' submetidos à atmosfera modificada ativa armazenados em câmara frigorífica a $10 \pm 1^{\circ} \mathrm{C}$ com $90 \pm 5 \%$ de UR, por 20 dias. 
TABELA 3 - Teores de acidez titulável (g de acido cítrico.100g polpa $\left.{ }^{-1}\right)$, potencial hidrogeniônico $(\mathrm{pH})$ e sólidos solúveis ( $\left.{ }^{\circ} \mathrm{Brix}\right)$ em abacates 'Hass' submetidos à atmosfera modificada ativa frigoarmazenados à $10 \pm 1^{\circ} \mathrm{C}$ com $90 \pm 5 \%$ de UR, por 25 dias.

\begin{tabular}{|c|c|c|c|c|c|c|c|}
\hline \multirow{2}{*}{ Tratamentos } & \multicolumn{6}{|c|}{ Dias de armazenamento } & \multirow{2}{*}{ Média geral } \\
\hline & $\mathbf{0}$ & 5 & 10 & 15 & 20 & 25 & \\
\hline \multicolumn{8}{|c|}{ Acidez titulável } \\
\hline I & $0,8 \mathrm{aB}$ & $2,1 \mathrm{aA}$ & $0,7 \mathrm{aB}$ & $0,5 \mathrm{aB}$ & $0,5 \mathrm{aB}$ & $0,4 \mathrm{aB}$ & $0,8 \pm 0,67 \mathrm{a}$ \\
\hline II & $0,8 \mathrm{aB}$ & $1,3 \mathrm{bA}$ & $0,7 \mathrm{aB}$ & $0,5 \mathrm{aC}$ & $0,3 \mathrm{aC}$ & $0,4 \mathrm{aC}$ & $0,7 \pm 0,36 \mathrm{~b}$ \\
\hline III & $0,8 \mathrm{aB}$ & $1,2 \mathrm{bA}$ & $0,6 \mathrm{aC}$ & $0,5 \mathrm{aC}$ & $0,3 \mathrm{aC}$ & $0,5 \mathrm{aC}$ & $0,7 \pm 0,31 \mathrm{~b}$ \\
\hline IV & $0,8 \mathrm{aA}$ & $1,2 \mathrm{bA}$ & $0,6 \mathrm{aB}$ & $0,4 \mathrm{aB}$ & $0,4 \mathrm{aB}$ & $0,5 \mathrm{aB}$ & $0,6 \pm 0,31 \mathrm{~b}$ \\
\hline $\mathbf{V}$ & $0,8 \mathrm{aA}$ & $1,0 \mathrm{bA}$ & $0,8 \mathrm{aA}$ & $0,5 \mathrm{aB}$ & $0,4 \mathrm{aB}$ & $0,5 \mathrm{aB}$ & $0,7 \pm 0,23 \mathrm{~b}$ \\
\hline Média geral de dias & $0,8 \mathrm{~A}$ & $\begin{array}{c}1,4 \\
\pm 0,43 \mathrm{~A}\end{array}$ & $\begin{array}{c}0,7 \\
\pm 0,08 \mathrm{~B}\end{array}$ & $\begin{array}{c}0,5 \\
\pm 0,04 \mathrm{C}\end{array}$ & $\begin{array}{c}0,4 \\
\pm 0,08 \mathrm{C}\end{array}$ & $\begin{array}{c}0,5 \\
\pm 0,05 \mathrm{C}\end{array}$ & \\
\hline & & & \multicolumn{3}{|c|}{ Potencial hidrogeniônico } & & \\
\hline I & 7,0 & 6,5 & 7,0 & 6,3 & 7,3 & 6,7 & $6,8 \pm 0,37$ \\
\hline II & 7,0 & 6,6 & 6,8 & 7,0 & 6,9 & 6,6 & $6,8 \pm 0,18$ \\
\hline III & 7,0 & 6,6 & 6,9 & 6,8 & 6,9 & 6,6 & $6,8 \pm 0,17$ \\
\hline IV & 7,0 & 6,6 & 6,7 & 6,9 & 7,0 & 6,6 & $6,8 \pm 0,19$ \\
\hline $\mathbf{V}$ & 7,0 & 6,7 & 6,7 & 6,8 & 7,0 & 6,6 & $6,8 \pm 0,17$ \\
\hline Média geral de dias & $7,0 \mathrm{~A}$ & $\begin{array}{c}6,6 \\
\pm 0,07 \mathrm{C}\end{array}$ & $\begin{array}{c}6,8 \\
\pm 0,13 \mathrm{~B}\end{array}$ & $\begin{array}{c}6,8 \\
\pm 0,27 \mathrm{~B}\end{array}$ & $\begin{array}{c}7,0 \\
\pm 0,16 \mathrm{~A}\end{array}$ & $\begin{array}{c}6,6 \\
\pm 0,04 \mathrm{C}\end{array}$ & \\
\hline \multicolumn{8}{|c|}{ Sólidos solúveis } \\
\hline I & $9,4 \mathrm{aA}$ & $9,4 \mathrm{aA}$ & $10,0 \mathrm{aA}$ & $9,2 \mathrm{bA}$ & $8,9 \mathrm{aA}$ & $8,0 \mathrm{aA}$ & $9,0 \pm 0,67 \mathrm{~b}$ \\
\hline II & 9,4 aA & $9,0 \mathrm{aA}$ & $9,0 \mathrm{aA}$ & $7,3 \mathrm{cB}$ & $9,0 \mathrm{aA}$ & $8,4 \mathrm{aA}$ & $8,7 \pm 0,75 \mathrm{~b}$ \\
\hline III & $9,4 \mathrm{aA}$ & $9,1 \mathrm{aA}$ & $9,8 \mathrm{aA}$ & $9,1 \mathrm{bA}$ & $7,3 \mathrm{bB}$ & $9,8 \mathrm{aA}$ & $9,0 \pm 0,92 \mathrm{~b}$ \\
\hline IV & $9,4 \mathrm{aA}$ & $8,8 \mathrm{aA}$ & $9,7 \mathrm{aA}$ & $8,7 \mathrm{bA}$ & $9,1 \mathrm{aA}$ & $8,7 \mathrm{aA}$ & $9,0 \pm 0,41 \mathrm{~b}$ \\
\hline V & $9,4 \mathrm{aB}$ & $9,2 \mathrm{aB}$ & $10,1 \mathrm{aB}$ & $12,0 \mathrm{aA}$ & $8,6 \mathrm{aB}$ & $9,2 \mathrm{aB}$ & $9,7 \pm 1,20$ a \\
\hline Média geral de dias & $\begin{array}{c}9,4 \\
\pm 0,0 \mathrm{~A}\end{array}$ & $\begin{array}{c}9,0 \mathrm{a} \\
\pm 0,22 \mathrm{~A}\end{array}$ & $\begin{array}{c}9,7 \\
\pm 0,43 \mathrm{~A}\end{array}$ & $\begin{array}{c}9,3 \\
\pm 1,71 \mathrm{~A}\end{array}$ & $\begin{array}{c}8,6 \\
\pm 0,74 \mathrm{~B}\end{array}$ & $\begin{array}{c}8,8 \\
\pm 0,70 \mathrm{~B}\end{array}$ & \\
\hline
\end{tabular}

Médias seguidas de mesma letra para os dias e para as concentrações não diferem entre si pelo Teste Skott-Knott à 1 e $5 \%$ de probabilidade, respectivamente. Médias seguidas de mesma letra minúscula na linha e maiúscula na coluna para a interação concentrações $\mathrm{X}$ dias não diferem entre si pelo Teste Scott-Knott à 5\% de probabilidade. 
TABELA 4- Firmeza $\left(\mathrm{gf} \mathrm{cm}^{-2}\right)$ obtida em abacates 'Hass' submetidos à atmosfera modificada ativa armazenados em câmara frigorífica à $10 \pm 1^{\circ} \mathrm{C} \operatorname{com} 90 \pm 5 \%$ de UR, por 25 dias.

\begin{tabular}{|c|c|c|c|c|c|c|c|}
\hline \multirow{2}{*}{ Concentrações } & \multicolumn{6}{|c|}{ Dias de armazenamento } & \multirow{2}{*}{$\begin{array}{l}\text { Média geral de } \\
\text { concentrações }\end{array}$} \\
\hline & 0 & 5 & 10 & 15 & 20 & 25 & \\
\hline $\mathbf{I}$ & 1018,5 & 1000,5 & 956,3 & 1018,9 & 1015,1 & 1017,7 & $1004,5 \pm 24,61$ \\
\hline II & 1018,5 & 1004,8 & 1021,2 & 987,0 & 1019,1 & 993,8 & $1007,4 \pm 14,55$ \\
\hline III & 1018,5 & 1013,9 & 1022,4 & 1019,5 & 1017,2 & 1022,5 & $1019,0 \pm 3,27$ \\
\hline IV & 1018,5 & 1015,7 & 1021,1 & 1028,8 & 1015,0 & 965,0 & $1010,7 \pm 22,93$ \\
\hline $\mathbf{V}$ & 1018,5 & 1009,4 & 1014,3 & 879,3 & 1018,3 & 1014,4 & $992,4 \pm 55,50$ \\
\hline Média geral de dias & $1018,5 \mathrm{a}$ & $\begin{array}{c}1008,9 \\
\pm 6,30 \mathrm{a}\end{array}$ & $\begin{array}{c}1007,0 \\
\pm 28,55 \mathrm{a}\end{array}$ & $\begin{array}{c}986,7 \\
\pm 62,09 \mathrm{a}\end{array}$ & $\begin{array}{l}1016,9 \\
\pm 1,85 \mathrm{a}\end{array}$ & $\begin{array}{r}1002,7 \\
\pm 23,74 a\end{array}$ & \\
\hline
\end{tabular}

Médias seguidas de mesma letra para os dias não diferem entre si pelo Teste Skott-Knott à $1 \%$ de probabilidade.

TABELA 5- Atividade das enzimas pectinametilesterase (UE $\min ^{-1} \mathrm{~g}^{-1}$ de tecido fresco) e poligalacturonase (UE $\min ^{-1} \mathrm{~g}^{-1}$ de tecido fresco) obtida em abacates 'Hass' submetidos à atmosfera modificada ativa armazenados em câmara frigorífica à $10 \pm 1^{\circ} \mathrm{C}$ com $90 \pm 5 \%$ de UR, por 25 dias.

\begin{tabular}{|c|c|c|c|c|c|c|c|}
\hline \multirow{2}{*}{ Concentrações } & \multicolumn{6}{|c|}{ Dias de armazenamento } & \multirow{2}{*}{$\begin{array}{c}\text { Médias de } \\
\text { de atividade }\end{array}$} \\
\hline & \multirow[t]{2}{*}{$\mathbf{0}$} & 5 & 10 & 15 & 20 & 25 & \\
\hline & & \multicolumn{3}{|c|}{ Pectinametilesterase } & & & \\
\hline $\mathbf{I}$ & $171,1 \mathrm{aB}$ & $191,1 \mathrm{bB}$ & $195,9 \mathrm{bB}$ & $252,5 \mathrm{aA}$ & $227,7 \mathrm{bA}$ & $186,1 \mathrm{bB}$ & $204,1 \pm 30,16 \mathrm{a}$ \\
\hline II & $171,1 \mathrm{aC}$ & $260,4 \mathrm{aB}$ & $167,1 \mathrm{bC}$ & $180,8 \mathrm{bC}$ & $331,8 \mathrm{aA}$ & $153,9 \mathrm{bC}$ & $210,8 \pm 70,32 \mathrm{a}$ \\
\hline III & $171,1 \mathrm{aA}$ & $145,3 \mathrm{bA}$ & $137,0 \mathrm{bA}$ & $172,0 \mathrm{bA}$ & $200,8 \mathrm{bA}$ & $184,7 \mathrm{bA}$ & $168,5 \pm 23,89 \mathrm{~b}$ \\
\hline IV & $171,1 \mathrm{aA}$ & $208,2 \mathrm{bA}$ & $180,0 \mathrm{bA}$ & $158,0 \mathrm{bA}$ & $172,4 \mathrm{cA}$ & $222,5 \mathrm{bA}$ & $185,3 \pm 24,70 \mathrm{~b}$ \\
\hline $\mathbf{V}$ & $171,1 \mathrm{aC}$ & $246,6 \mathrm{aB}$ & $257,1 \mathrm{aB}$ & $113,0 \mathrm{bC}$ & $125,5 \mathrm{cC}$ & $312,5 \mathrm{aA}$ & $204,3 \pm 79,91 \mathrm{a}$ \\
\hline \multirow[t]{2}{*}{$\begin{array}{c}\text { Média geral } \\
\text { de dias }\end{array}$} & $171,1 \mathrm{~B}$ & $\begin{aligned} & 210,3 \\
\pm & 45,90 \mathrm{~A}\end{aligned}$ & $\begin{aligned} & 187,4 \\
\pm & 44,54 \mathrm{~B}\end{aligned}$ & $\begin{aligned} & 175,3 \\
\pm & 50,45 \mathrm{~B}\end{aligned}$ & $\begin{array}{r}211,6 \\
\pm 77,09 \mathrm{~A}\end{array}$ & $\begin{aligned} & 211,9 \\
\pm & 61,24 \mathrm{~A}\end{aligned}$ & \\
\hline & & \multicolumn{3}{|c|}{ Poligalacturonase } & & & \\
\hline I & $47,8 \mathrm{aA}$ & $267,8 \mathrm{aA}$ & $198,5 \mathrm{bA}$ & $171,6 \mathrm{aA}$ & $89,4 \mathrm{aA}$ & 229,9 aA & $167,5 \pm 84,10$ \\
\hline II & $47,8 \mathrm{aB}$ & $246,7 \mathrm{aA}$ & $61,7 \mathrm{bA}$ & $101,8 \mathrm{aA}$ & $10,1 \mathrm{aA}$ & $243,8 \mathrm{abA}$ & $118,6 \pm 102,36$ \\
\hline III & $47,8 \mathrm{aB}$ & $253,5 \mathrm{aAB}$ & $140,6 \mathrm{abAB}$ & $12,5 \mathrm{aB}$ & $17,8 \mathrm{aB}$ & $314,4 \mathrm{aA}$ & $131,0 \pm 128,46$ \\
\hline IV & $47,8 \mathrm{aB}$ & $269,6 \mathrm{aAB}$ & $372,0 \mathrm{aA}$ & $33,0 \mathrm{aB}$ & $104,6 \mathrm{aB}$ & $383,1 \mathrm{aA}$ & $201,7 \pm 160,05$ \\
\hline $\mathbf{V}$ & $47,8 \mathrm{aB}$ & $268,1 \mathrm{aA}$ & $267,8 \mathrm{aA}$ & 217,9 aA & $55,3 \mathrm{aB}$ & $37,8 \mathrm{bB}$ & $149,1 \pm 113,51$ \\
\hline $\begin{array}{c}\text { Média geral } \\
\text { de dias }\end{array}$ & $47,8 \mathrm{~B}$ & $\begin{array}{c}261,1 \\
\pm 10,38 \mathrm{~A}\end{array}$ & $\begin{array}{c}208,1 \\
\pm 118,85 \mathrm{a}\end{array}$ & $\begin{array}{c}107,3 \\
\pm 87,90 \mathrm{~B}\end{array}$ & $\begin{array}{c}55,4 \\
\pm 41,96 \mathrm{~B}\end{array}$ & $\begin{array}{c}241,8 \\
\pm 129,42 \mathrm{~A}\end{array}$ & \\
\hline
\end{tabular}

Médias seguidas de mesma letra para os dias e para as concentrações não diferem entre si pelo Teste Skott-Knott à 1\% de probabilidade. Médias seguidas de mesma letra minúscula na linha e maiúscula na coluna para a interação concentrações X dias não diferem entre si pelo Teste Scott-Knott à $1 \%$ de probabilidade. 


\section{CONCLUSÕES}

A atmosfera modificada ativa, associada ao armazenamento refrigerado, é efetiva na conservação dos abacates 'Hass', resultando em baixo percentual de perda de massa e manutenção dos valores de firmeza. O tratamento em que os frutos foram submetidos à pressão parcial de $4,0 \mathrm{kPa}$ de $\mathrm{O}_{2}+7,0$ $\mathrm{kPa}$ de $\mathrm{CO}_{2}$ (T IV) foi o mais efetivo na conservação dos mesmos, principalmente devido à menor perda de massa, até o $20^{\circ}$ dia, e baixa produção de $\mathrm{CO}_{2} \mathrm{em}$ relação aos demais tratamentos.

\section{AGRADECIMENTOS}

À empresa Jaguacy (Bauru-SP), pelo apoio e participação nas pesquisas; à CAPES e Fundação de Apoio à Pesquisa no Estado de São Paulo.

\section{REFERÊNCIAS}

AHMED, D.M.; AHMED, F.M.; EL-MONGY, A.; ABU-AZIZ, B.;YOUSEF, A.R. Postharvest storage of Hass and Fuerte avocados under modified atmosphere conditions. Journal of Applied Sciences Research, Georgia, v.3, n.4, p. 267-274, 2007.

AWAD, M.; YOUNG, R. E. Postharvest variation in cellulase, polygalacturoanse, and pectinmethylesterase in avocado (Persea americana Mill, cv.Fuerte) fruits in relation to respiration and ethylene production. Plant Physiology, Mimeapolis, v.64, p.306-308, 1979.

BÁEZ-SAÑUDO, R.; BRINGAS, T.E.; GONZÁLES, A.G.; OJEDA, C.J.; MENDOZA, W. A. ; RAMOS, C.G. Evaluación de películas comestibles sobre la vida postcosecha del mango. Proceedings of the International Society Tropical Horticultural, Miami, v.41, p. 172-178, 2001.

BEN-ARIE, R.; ZUTKHI, Y. Extending the storage life of 'Fuyu' persimmon by modified-atmosphere packaging. Hortscience, Alexandria, v.27, n.7, p. 811-813,1992.

BLEINROTH, E.W.; ZUCCHINI, A.G.; POMPEO, R.M. Determinação das características físicas e mecânicas de variedade de abacate e sua conservação pelo frio. Coletânea ITAL, Campinas, v.7, n.1, p.29-81, 1976.
BRACKMANN, A.; HUNSCHE, M.; BALEM, T.A. Efeito de filmes de PVC esticável e polietileno no acúmulo de $\mathrm{CO}_{2}$ e na manutenção da qualidade póscolheita de morangos cv. Tangi. Revista Brasileira de Agrociência , Pelotas, v.5, n.2., p.89-92, 1999.

BRUMMEL, D. A. ; DAL CIN ,V.; CRISOSTO, C.H.; LABAVITCH, J.M. Cell wall metabolism during maturation, ripening and senescence of peach fruit. Journal of Experimental Botany, Oxford, v. 55, n.405, p. 2.029-2.039, 2004.

BUESCHER, R.W.; FURMANCSKI, R.J. Role of pectinmetilesterase and polygalacturonase in the formation of woolliness in peaches. Journal of Food Science, Chicago, v.43, p.264-266, 1978.

CHIN, L.H.; MOHD.ALI, Z.; LAZAN, H. Cell wall modification, degrading enzymes and softening of carambola fruit during ripening. Journal of Experimental Botany, Oxford, v.50, n.335, p. 767-775, 1999.

CHITARRA, M.I.F.; CHITARRA, A.B. Pós-colheita de frutos e hortaliças: fisiologia e manuseio. Lavras: Ed UFLA, 2005. 785 p.

DAIUTO, E.R.; TREMOCOLDI, M.A.; VIEITES, R.L. Conservação pós-colheita de abacate 'Hass' irradiado. Revista Iberoamericana de Tecnologia Postcosecha, México, v.10, n.2, p. 94-100, 2010a.

DAIUTO, E.R.; VIEITES, R.L.; TREMOCOLDI, M.A.; RUSS0, V.C. Taxa respiratória de abacate 'Hass' submetido a diferentes tratamentos físicos. Revista Iberoamericana de Tecnologia Postcosecha, México, v.10,n.2, p.101-109, 2010b.

FILGUEIRAS, H. A. C. Bioquímica do amadurecimento de tomates híbridos heterozigotos no loco 'alcobaça'. 1996. 118f. Tese (Doutorado em Ciência dos Alimentos) - Universidade Federal de Lavras, Lavras, 1996.

HOBSON, G. E. Pectinesterase in normal and abnormal tomato fruit. Biochemical Journal, New Zealand, v.86, p.358-365, 1963.

HUlTiN, H. O.; SUN, B.; BUlGER, J. Pectin methyl esterases of the banana: purification and properties. Journal of Food Science, Chicago, v. 31, n. 3, p. 320-327, May/June 1966 
IANNETA, P.P.M. et al. The role of ethylene and cell wall modifying enzymes in raspberry (Rubusidaeus) fruit ripening. Physiologia Plantarum, Copenhagen, v.105, p.338-347, 1999.

INSTITUTO ADOLFO LUTZ. Métodos físicoquímicos para análise de alimentos. São Paulo, 2008. $1020 \mathrm{p}$.

JOHNSTON J.W.; HEWETT, E. W.; HERTOG, M.L.A.T.M. Postharvest softening of apple (Malus domestica) fruit: a review. New Zealand Journal of Crop and Horticultural Science, Wellington, v.30, p.145-160, 2002.

JOYCE, D.C.; SHORTET, A.J.; JONES, P.N. Effect of delayed film wrapping and waxing on the shelf life of avocado fruit. Australian Journal of Experimental Agriculture, Melbourne, v.35, p.657-659, 1995.

LOURENÇO, E. J.; ATUTANI, A.T. Purification and properties of pectinesterase from papaya. Journal of the Science of Food and Agriculture, London, v.35,p.1120-1127, 1984.

NÉLSON, N.A. Pthotometric adaptation of the Somogy method for the determination of glucose. The Journal of Biological Chemistry, Bethesda, v. 153 , p. $375-380,1944$.

OLIVEIRA, F. E. R.; ABREU, C.M.P.; ASMAR, S.A.; CORREAA, A.D.; SANTOS, C.D. Firmeza de pêssegos 'Diamante' tratados com 1-MCP. Revista Brasileira de Fruticultura, Jaboticabal, v. 27, n.3, p. 366-368, 2005.

OLIVEIRA, M. A. de; SANTOS, C.H.; HENRIQUE, C.M.; DOMINGOS, J.R.D. Ceras para conservação pós-colheita de frutos de abacateiro fuerte, armazenados em temperatura ambiente. Scientia Agricola, Piracicaba, v.57, n.4, p.777-780, 2000.
PRASANNA, V.; YASHODA, H.M.; PRABHA, T.N.; THARANATHAN, R.N. Pectic polysaccharides during ripening of mango (Mangifera indica $\mathrm{L}$.). Journal of the Science of Food and Agriculture, London, v. 83, n.11, p.1182-1186, 2003.

RESENDE, J. M.; CHITARRA, M.I.F.; MALUF, W.R.; CHITARRA, A.B.; SAGGIN JR., O.J. Atividades de enzimas pectinametilesterase e poligalacturonase durante o amadurecimento de tomates do grupo multilocular. Horticultura Brasileira, Brasília, v.22, n.2, p. 206-212, 2004.

SALES, A. N. de; BOTREL, N.; COELHO, A. H. R. Aplicação de 1-metilciclopropeno em banana 'prataanã' e seus efeitos sobre as substâncias pécticas e enzimas pectinolíticas. Ciência e Agrotecnologia, Lavras, v.28, n.3, p.479-487, 2004.

SEYMOUR, G.B.; TUCKER, G.A. Avocado. In: SEYMOUR, G.B.; TAYLOR, J.E.; TUCKER, G.A. Biochemistry of fruit ripening. London: Chapman \& Hall, 1993. p. 53-76.

SOMOGY, M. Determination of blood sugar. Journal of Biological Chemistry, Bethesda, v.160, p.69-73, 1945.

TEIXEIRA, C.G.; BLEINROTH, E.W.; CASTRO, J.V.; MARTIN, Z.J.; TANGO, J.S.; TURATTI, J. M.; LEITE, R.S.S.F.; CASTRO, A.E.B. Abacate: cultura, matéria-prima, processamento e aspectos econômicos. Campinas: ITAL, 1991. 250p.

VIEITES, R.L.; DAIUTO, E.R.; FUMES, J.F.F. Capacidade antioxidante e qualidade pós- colheita de abacate 'Fuerte'. Revista Brasileira de Fruticultura, Jaboticabal, v.34, n.2, p.336-348, 2012. 